\title{
A PRODUÇÃO DO CONHECIMENTO SOBRE O ENSINO DE QUÍMICA NAS REUNIÕES ANUAIS DA SOCIEDADE BRASILEIRA DE QUÍMICA: UMA REVISÃO
}

\author{
Cristiane Andretta Francisco e Salete Linhares Queiroz* \\ Instituto de Química de São Carlos, Universidade de São Paulo, CP 780, 13560-970 São Carlos - SP, Brasil
}

Recebido em 9/11/07; aceito em 14/5/08; publicado na web em 16/10/08

\begin{abstract}
THE PRODUCTION OF KNOWLEGDE OF CHEMICAL EDUCATION AT THE ANNUAL MEETINGS OF THE BRAZILIAN CHEMICAL SOCIETY: A REVIEW. This paper discusses the Brazilian academic production on Chemical Education. The main source of information is the annual meeting of the Brazilian Chemical Society (RASBQ) covering the period 1999-2006. All the papers presented by the Division of Chemical Education of the RASBQ were reviewed to permit a discussion about the development of the area in Brazil. This bibliographical revision comprises the following aspects: year of presentation, Brazilian region and institution of production, scholastic level encompassed by the study, the kind of academic work (or research type) and thematic focus of the study.
\end{abstract}

Keywords: state of the art; Chemical Education; Brazilian academic production.

\section{INTRODUÇÃO}

Nos últimos 25 anos, trabalhos de caráter bibliográfico ("estado da arte" ou "estado do conhecimento") têm sido realizados no país visando o mapeamento e a discussão de uma determinada produção acadêmica, em diversos campos do conhecimento. Esses trabalhos buscam definir aspectos e dimensões destacadas e privilegiadas, em diferentes épocas e lugares, as formas e as condições de produção de dissertações de mestrado, teses de doutorado, publicações em periódicos e comunicações em anais de congressos e de seminários. ${ }^{1}$

Conforme reflete Ferreira, ${ }^{2}$ os pesquisadores responsáveis pelo desenvolvimento de trabalhos de tal natureza "parecem ter vivido um determinado período em que se constata uma produção de estudos e de pesquisas sobre determinada área do conhecimento que apresenta crescimento tanto quantitativo quanto qualitativo, porém pouco divulgada, pouco analisada e articulada". Além disso, argumenta Ferreira, ${ }^{2}$ os pesquisadores "parecem querer responder a uma determinada demanda social que lhes cobra propostas/soluções para certos problemas, principalmente o reiterado fracasso da escola brasileira". Movidos por percepções similares, e tendo em vista o acréscimo considerável de estudos dedicados à Educação em Química no país, decidimos somar-nos a este rol de pesquisadores, objetivando um melhor conhecimento e compreensão da área em questão. Para tanto, tomamos como objetos de estudo os trabalhos apresentados nas Reuniões Anuais da Sociedade Brasileira de Química (RASBQs), especificamente na seção de Ensino de Química (ED), no intervalo de 1999 a 2006. Os trabalhos foram classificados e analisados de acordo com o ano de apresentação, a instituição de origem (e conseqüentemente a região geográfica de origem), o nível de escolaridade, o foco temático de estudo abrangido e o gênero de trabalho acadêmico. Estes foram selecionados para análise tendo em vista o papel fundamental desempenhado pela Sociedade Brasileira de Química (SBQ) para o desenvolvimento das pesquisas na área de Educação em Química e a credibilidade que as Reuniões por ela promovidas possuem junto à comunidade científica, assim como a sua abrangência.

Até onde vai o nosso conhecimento, encontram-se relatados na literatura 2 trabalhos de caráter bibliográfico que versam so-

*e-mail: salete@iqsc.usp.br bre a Educação em Química no Brasil: o primeiro, intitulado "A educação química no Brasil: uma visão através das pesquisas e publicações da área", ${ }^{3}$ foi publicado em 2000, na revista Educación Química, e analisou o desenvolvimento da área, considerando a produção acadêmica de teses de doutorado e dissertações de mestrado no período de 1972 a 1996 e de artigos publicados nas revistas Química Nova (seção Educação) e Química Nova na Escola, no período de 1995 a 1998. O segundo, intitulado "A pesquisa em ensino de química no Brasil: conquistas e perspectivas", ${ }^{4}$ foi publicado nesta revista em 2002 e investigou os artigos das revistas Química Nova na Escola e Química Nova (seção Educação), os trabalhos apresentados na seção de Ensino de Química das RAS$\mathrm{BQs}$ e os resumos de teses e dissertações produzidas na área, no intervalo de 1977 a 2001.

A metodologia de coleta e análise de dados e os intervalos de tempo investigados nos referidos trabalhos ${ }^{3,4}$ se diferenciam daqueles adotados para a produção deste artigo. No entanto, algumas discussões aqui desenvolvidas foram tecidas à luz de considerações neles apresentadas. Assim, acreditamos que o presente trabalho os complementa e atualiza.

Cabe também destacar que os resumos aqui analisados não representam a totalidade dos trabalhos acadêmicos apresentados em eventos científicos na área em questão, no intervalo de tempo em estudo. Uma quantidade considerável de trabalhos foi também apresentada em eventos de grande importância e tradição, como os Encontros Nacionais de Ensino de Química (ENEQs) e os Encontros de Debates sobre o Ensino de Química (EDEQs). Neste contexto, uma investigação aprofundada dos vários fatores que colaboram para delinear o perfil do Ensino de Química no Brasil não é viável a partir apenas dos resumos considerados no presente trabalho. Ainda assim, importantes considerações, que julgamos de grande valia para a comunidade de interessados neste Ensino, foram elaboradas a partir da análise dos mesmos.

\section{METODOLOGIA DE PESQUISA}

Este trabalho refere-se a uma análise dos resumos apresentados na seção de ED, nas RASBQs, no período de 1999 a 2006. Uma vez reunidos todos os resumos, as seguintes etapas foram seguidas: definição dos aspectos a serem considerados na classificação e descrição 
dos trabalhos em estudo; organização dos dados bibliográficos e de informações complementares em uma ficha de classificação; leitura e classificação dos documentos com relação aos aspectos definidos anteriormente; organização dos resultados da classificação dos documentos, com relação aos vários aspectos analisados, em forma de tabelas e gráficos; análise dos resultados e elaboração das principais tendências verificadas nos documentos.

Os trabalhos foram classificados da seguinte maneira: ano de apresentação; instituição de vínculo dos autores; região geográfica brasileira a que pertence; nível de escolaridade; foco temático e gênero de trabalho acadêmico. Para a análise dos níveis e dos focos temáticos, adotamos as descrições presentes no trabalho de Megid Neto. ${ }^{5}$ Para determinar a forma de análise do gênero dos trabalhos levamos em consideração a assertiva de Schnetzler, ${ }^{4}$ que concluiu pela existência, entre os resumos das RASBQs por ela estudados, tanto de trabalhos de pesquisa/investigação propriamente ditos, quanto de trabalhos "que não correspondem propriamente a investigações, mas sim, a descrições de inovações pedagógicas que incluem propostas de ensino ou de atividades práticas de laboratório, e a relatos de experiência". Nesta perspectiva, diferenciamos os trabalhos por nós analisados em 2 grupos: o primeiro inclui trabalhos de investigação/ pesquisa e o segundo, trabalhos que descrevem inovações pedagógicas e relatos de experiência. Para a realização da análise também nos valemos da concepção de Soares ${ }^{6}$ que diferencia os gêneros dos trabalhos segundo a sua relação com a realidade ou com o fenômeno investigado: quando o texto corresponde à representação do sucedido, a autora considera-o um relato de experiência; se corresponde à representação do investigado, é designado por pesquisa.

Faz-se necessário ainda esclarecer alguns aspectos pertinentes à elaboração e forma de divulgação dos resumos que foram analisados: a) nos anos de 1999 e 2000 os resumos foram dispostos em 2 colunas por página em Livro de Resumos. Neles deveriam constar: título do trabalho, nome dos autores, a categoria de cada autor (pesquisador, professor do ensino fundamental/médio, pós-graduando ou graduando), instituição a que cada autor se vincula e 3 palavras-chave. O texto do resumo deveria conter introdução, objetivos, métodos, resultados, conclusões e bibliografia. Estes resumos encontram-se impressos nos Livros de Resumos da $22^{\mathrm{a}}$ e $23^{\mathrm{a}}$ RASBQ; b) nos anos de 2001 a 2005 foram adotados 2 modelos de resumo (templates). No primeiro deveriam ser inseridos: o título do trabalho, os nomes e endereços dos autores, 3 palavras-chave e um pequeno resumo, em aproximadamente 1/5 de uma folha de papel A4. Estes resumos encontram-se impressos nos Livros de Resumos da $24^{\mathrm{a}}$ a $28^{\mathrm{a}}$ RASBQ. $\mathrm{Na} 29^{\mathrm{a}} \mathrm{RASBQ}$, ocorrida em 2006, o primeiro tipo de template não foi adotado, apenas o segundo tipo. Nele deveriam estar contidos, em aproximadamente uma folha de papel A4, todos os elementos do primeiro template, exceto o pequeno resumo, que deveria ser substituído por um texto contendo introdução, resultados e discussão, conclusões e referências bibliográficas. Estes resumos encontram-se disponibilizados no site da SBQ (www.sbq.org.br) em arquivo PDF, e não estão impressos em Livros de Resumos. Os resumos da $29^{a}$ RASBQ encontram-se também disponibilizados em CD-ROM.

Ao iniciarmos a separação e impressão dos trabalhos da seção de Ensino de Química, encontramos um obstáculo no ano de 2001. Apesar de conseguirmos acessar o site da SBQ onde estão disponibilizados os trabalhos da $24^{\mathrm{a}} \mathrm{RASBQ}$, não foi possível fazer o download de nenhum dos trabalhos. Assim, analisamos apenas os resumos que constavam do Livro de Resumos da Reunião, ocorrida em 2001. Uma vez que as informações aí apresentadas são extremamente restritas, a análise dos resumos apresentados no ano de 2001 foi realizada de maneira diferenciada das demais, abrangendo apenas os seguintes aspectos: ano de apresentação, instituição de vínculo dos autores e região geográfica brasileira a que pertence.

\section{RESULTADOS E DISCUSSÃO}

\section{A produção e sua distribuição no tempo e representatividade}

No levantamento feito dos trabalhos apresentados nas 8 últimas RASBQs, na seção de ED, encontramos 1008 trabalhos. A sua distribuição no tempo é apresentada na Figura 1, que evidencia o aumento, de forma praticamente ininterrupta, do número de trabalhos apresentados na seção, de 1999 a 2004. Tal constatação também foi alcançada por Schnetzler, ${ }^{4}$ para o período 1977 a 2001. O decréscimo considerável no número de trabalhos apresentados em 2005, em relação ao número apresentado em 2004, é devido ao fato dessa RASBQ ter ocorrido juntamente com o XXVI Congreso Latinoamericano de Química. Na ocasião, 52 trabalhos foram apresentados na seção exclusivamente por pesquisadores de outros países, o que reduz a produção nacional a 142 trabalhos, e a aproxima da produção dos demais anos investigados, consolidando a tendência de crescimento do número de trabalhos até 2005. Em contrapartida, no ano de 2006 ocorre uma diminuição significativa no número de trabalhos apresentados na seção. Neste ano foi também realizado em Campinas, 2 meses após a RASBQ (que ocorreu em Águas de Lindóia), o XIII Encontro Nacional de Ensino de Química (ENEQ), com a apresentação de 334 trabalhos. ${ }^{7}$ Provavelmente os pesquisadores, em particular os da região Sudeste, que colaboram com um montante expressivo de trabalhos nas RASBQs, optaram por apresentar seus trabalhos no ENEQ, que visa exclusivamente a discussão de aspectos concernentes ao Ensino de Química, levando ao decréscimo observado no número de trabalhos apresentados na RASBQ.

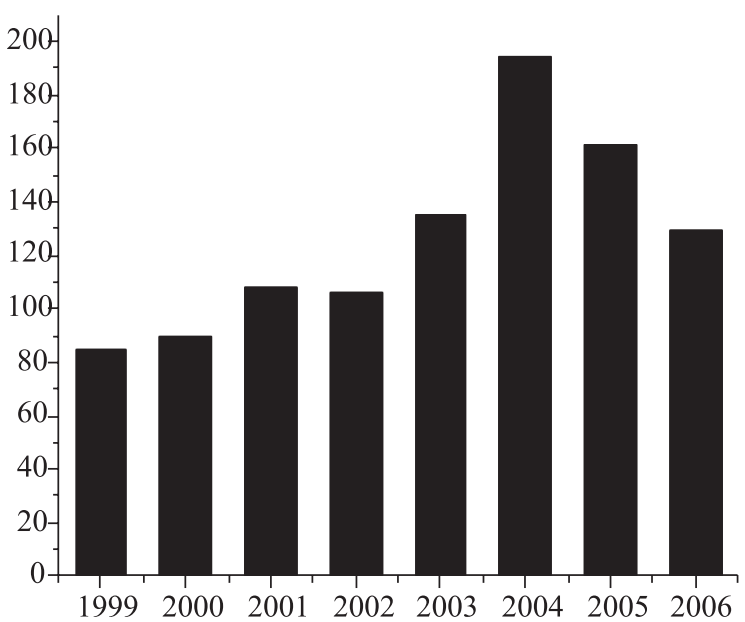

Figura 1. Distribuição dos resumos na seção de ED no período de 1999 a 2006

Embora a análise dos trabalhos apresentados no ano de 2007 não seja objetivo do presente manuscrito, neste ano foram apresentados 164 trabalhos, ${ }^{8}$ o que indica a retomada no crescimento do número de trabalhos apresentados na seção.

Uma visão geral sobre a representatividade de todas as seções integrantes das RASBQs nos últimos 8 anos pode ser obtida a partir da observação da Tabela 1. Os trabalhos da seção de ED representam, em média, 6,71\% dos resumos apresentados nos encontros, o que demonstra uma demanda razoável para a área, que se equipara à maioria das demais, sendo acentuadamente superada apenas por áreas clássicas da Química (Analítica, Orgânica e Inorgânica) e pelas áreas de Produtos Naturais, Química de Materiais, Eletroquímica e Eletroanalítica e Química Ambiental, de forte tradição em pesquisa no país.

Os dados apresentados sugerem o amadurecimento da área em estudo e o fortalecimento de uma comunidade preocupada com a melhoria do ensino de Química no Brasil. 
Tabela 1. Número (absoluto e relativo) de resumos apresentados por seção nas RASBQs no período de 1999 a 2006

\begin{tabular}{lcc}
\hline Área / Seção & \multicolumn{2}{c}{$\begin{array}{c}\text { Número de Representatividade } \\
\text { resumos }\end{array}$} \\
\hline História da Química & 64 & 0,43 \\
Química de Superfícies e Colóides & 138 & 0,92 \\
Fotoquímica & 232 & 1,55 \\
Química Tecnológica & 383 & 2,55 \\
Química Teórica & 426 & 2,84 \\
Química Biológica & 431 & 2,87 \\
Catálise & 451 & 3,00 \\
Química Medicinal & 617 & 4,11 \\
Físico-Química & 706 & 4,70 \\
Ensino de Química & 1008 & 6,71 \\
Química Ambiental & 1118 & 7,44 \\
Eletroquímica e Eletroanalítica & 1122 & 7,47 \\
Química de Materiais & 1381 & 9,20 \\
Química Inorgânica & 1419 & 9,45 \\
Química Orgânica & 1635 & 10,89 \\
Química Analítica & 1842 & 12,26 \\
Química de Produtos Naturais & 2044 & 13,61 \\
Total & 15017 & 100,00 \\
\hline
\end{tabular}

A produção e sua distribuição de acordo com as regiões brasileiras

O número de trabalhos apresentados nas RASBQs no período compreendido entre 1999 e 2006, de acordo com a distribuição por regiões geográficas do Brasil, encontra-se na Tabela 2. Cabe esclarecer que dentre os 1008 trabalhos mencionados anteriormente, apenas 942 foram considerados nesta análise, uma vez que os 52 trabalhos procedentes exclusivamente do exterior, apresentados na $27^{\mathrm{a}} \mathrm{RASBQ}$, não foram contabilizados. Foram ainda excluídos da análise 12 resumos, que não indicavam nem a instituição nem o endereço dos autores. Os trabalhos ED-022(1999) e ED-092(2005) foram também excluídos. Tudo leva a crer, a partir da análise do conteúdo expresso no ED022(1999), que este foi anexado equivocadamente à seção de ED. O ED-092(2005), por sua vez, é idêntico ao trabalho ED-049(2005). É necessário destacar ainda que na Tabela 2 o número de trabalhos excede os 942 mencionados anteriormente, uma vez que cada trabalho apresentado por 2 autores provenientes de regiões diferentes foi computado 2 vezes (1 vez para cada região). Considerando que 25 trabalhos foram apresentados em parceria por autores de 2 regiões diferentes, o número de trabalhos computados na Tabela 2 é de 967. Todos os percentuais foram calculados sobre 942 trabalhos.

A maioria dos trabalhos é proveniente da região Sudeste, representando $60,61 \%$ do total apresentado. O fato da região abrigar um número elevado de Instituições de Ensino Superior (IES) de grande tradição em pesquisa no país, como a Universidade de São Paulo
(USP), Universidade Federal do Rio de Janeiro (UFRJ) e Universidade Federal de Minas Gerais (UFMG), justifica, em parte, a relevante contribuição. Há ainda outro aspecto que pode justificar o fato da região Sudeste apresentar a maioria dos trabalhos nas RASBQs no período investigado. Das 8 Reuniões, 7 foram realizadas no Sudeste (6 no estado de Minas Gerais e 1 no estado de São Paulo), aspecto que aparentemente favoreceu muito a apresentação de trabalhos. De fato, podemos avaliar a relevância deste aspecto quando observamos que na ocasião em que o evento foi sediado na região Nordeste, em 2004, o número de trabalhos da região praticamente dobrou em relação aos 2 anos anteriores e posteriores.

As regiões Nordeste e Sul colaboraram, respectivamente, com 16,66 e $13,91 \%$ dos trabalhos apresentados. No Nordeste, um número considerável de resumos é proveniente dos estados de Pernambuco, Bahia e Sergipe, em comparação com os demais estados. A região Centro-oeste teve uma produção inferior à das regiões Nordeste e Sul, sendo a maior parte dos trabalhos proveniente do Distrito Federal e do estado de Goiás.

Apenas 6 trabalhos são originários da região Norte: 2 da Universidade Federal do Pará (UFPA) e 4 da Universidade Federal de Roraima (UFRR). Provavelmente, o isolamento típico do local e o seu distanciamento do Sudeste podem explicar, em parte, o pequeno número de resumos apresentados. No entanto, em outras seções das RASBQs são encontrados trabalhos provenientes da região Norte, com especial destaque na seção de Produtos Naturais, onde foram apresentados 31 trabalhos da região em 2006. Assim, o número reduzido de resumos na seção de ED pode ser devido também à pouca atividade de pesquisa na área.

Mencionamos anteriormente que existem 25 trabalhos que contam com a participação de pesquisadores de instituições de regiões diferentes na sua produção. A maioria das parcerias na produção de trabalhos provenientes de diferentes regiões foi estabelecida entre os pesquisadores das regiões Sudeste e Centro-oeste, Sudeste e Nordeste, e Sudeste e Sul, sendo as seguintes parcerias dignas de nota: Gerson de S. Mól (que até a $23^{\text {a }}$ RASBQ é identificado como pesquisador da UFMG e depois passa a ser identificado como pesquisador da Universidade de Brasília (UnB) e Eduardo F. Mortimer (região Sudeste) com Wildson L. P. Santos e Roberto R. Silva (região Centro-oeste); Roseli P. Schnetzler (região Sudeste) com Lenir B. Zanon (região $\mathrm{Sul}$ ). As demais parcerias ocorreram, com pouca regularidade, entre grupos diversificados.

Existem apenas 2 trabalhos que foram realizados a partir de parcerias entre pesquisadores de IES do Brasil e de outros países. $\mathrm{O}$ primeiro consta de uma parceria da UnB com a Pädagogische Hochschule Ludwigsburg (Alemanha) e o segundo de parceria da Universidad Central de Las Villas (Cuba) com o Centro Federal de Educação Tecnológica do Rio de Janeiro (CEFET-RJ).

Considerando que o estabelecimento de parcerias acadêmicas pode conduzir ao aumento e à diversificação da produção de trabalhos científicos, assim como favorecer o fortalecimento de determinadas linhas de pesquisa em regiões onde ainda são incipientes, é desejável que o panorama acima delineado para a área de Educação em Química

Tabela 2. Distribuição dos resumos apresentados na seção de ED nas RASBQs de acordo com as regiões geográficas brasileiras no período de 1999 a 2006

\begin{tabular}{lccccccccrrr}
\hline Região geográfica & 1999 & 2000 & 2001 & 2002 & 2003 & 2004 & 2005 & 2006 & Total & $(\%)$ \\
\hline Norte & - & - & 1 & - & - & 1 & 3 & 1 & 6 & 0,64 \\
Centro-oeste & 9 & 7 & 8 & 10 & 14 & 15 & 22 & 17 & 102 & 10,82 \\
Sul & 8 & 12 & 13 & 16 & 25 & 19 & 17 & 21 & 131 & 13,91 \\
Nordeste & 21 & 13 & 13 & 19 & 21 & 38 & 19 & 13 & 157 & 16,66 \\
Sudeste & 49 & 61 & 74 & 67 & 79 & 68 & 101 & 72 & 571 & 60,61 \\
\hline
\end{tabular}


seja gradativamente modificado, especialmente no que diz respeito às interações entre parceiros de regiões brasileiras nas quais a pesquisa na área ainda se encontra em fase de consolidação com aqueles de regiões onde tal etapa já foi superada.

\section{A produção e sua distribuição de acordo com as instituições acadêmicas}

Outra questão importante diz respeito às IES as quais estão vinculados os autores dos trabalhos. No entanto, nem todos os resumos foram considerados nesta análise: dos 1008 trabalhos pertencentes à seção de ED, 52 deles não foram contabilizados por serem procedentes exclusivamente do exterior. Os trabalhos ED-022(1999) e ED-092(2005), mencionados anteriormente, também não foram contabilizados, 35 outros trabalhos também não o foram, porque não mencionam a instituição de vínculo dos autores (embora alguns mencionem o endereço do autor e tenham sido considerados na análise da distribuição da produção de acordo com as regiões brasileiras). Assim, são 919 trabalhos que fazem parte da análise realizada neste tópico.

A Figura 2 apresenta a classificação das 16 IES de maior produção. Do total de trabalhos analisados, $73,12 \%$ da produção está a elas restrita: 10 estão localizadas na região Sudeste, 3 na região Nordeste, 2 na região Centro-oeste e 1 na região Sul.

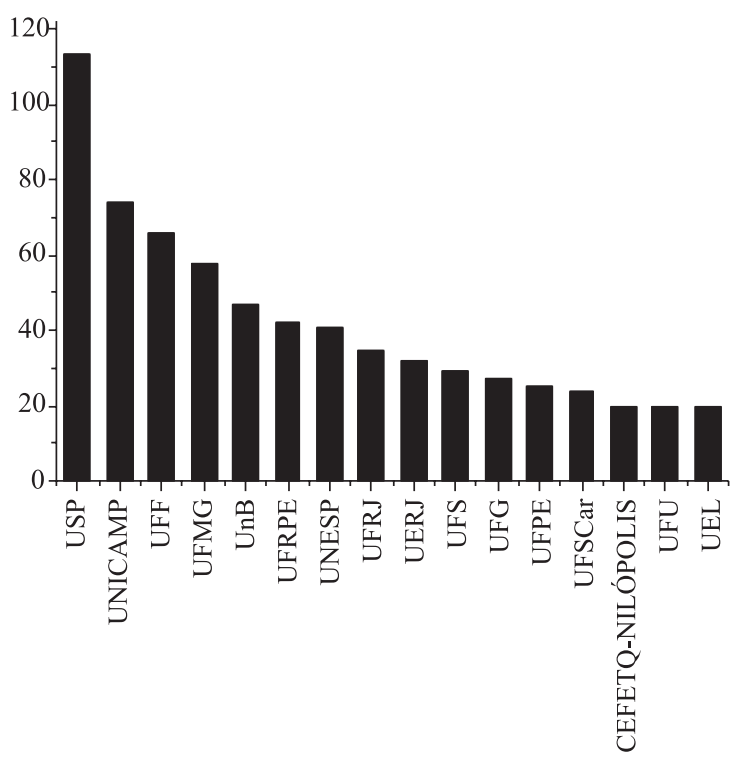

Figura 2. Gráfico de distribuição de IES com maior número de trabalhos apresentados na seção de ED nas RASBQs no período de 1999 a 2006

$\mathrm{Na}$ instituição com o maior percentual de produção, a USP, os trabalhos apresentados resultam dos esforços de mais de um grupo de pesquisa. Na verdade, o total de trabalhos é proveniente tanto do Instituto de Química e da Faculdade de Educação (campus de São Paulo) quanto de unidades em seus campi do interior. Outras instituições também apresentaram esta característica: vários trabalhos produzidos pela Universidade Estadual Paulista (UNESP) são provenientes de esforços de pesquisadores distribuídos em várias unidades em seus campi.

A partir da constatação de quais IES apresentaram o maior número de trabalhos nas RASBQs, verificamos também quais grupos se destacaram em cada uma delas. Observamos que na USP, dos 113 trabalhos apresentados pela instituição, $10,60 \%$ são provenientes do grupo liderado por Maria Eunice R. Marcondes, do Instituto de Química, e 10,60\% do grupo liderado por Marcelo Giordan, da Faculdade de Educação (os referidos grupos são sediados no campus de São Paulo). No campus de São Carlos a maioria dos trabalhos foi produzida no Instituto de Química de São Carlos, no grupo liderado por Salete L. Queiroz (8,85\% do total de trabalhos), e no campus de Ribeirão Preto, no grupo liderado por Yassuko Iamamoto (5,30\% do total de trabalhos), do Departamento de Química.

As outras universidades de maior produção da região Sudeste são Universidade Estadual de Campinas (UNICAMP), Universidade Federal Fluminense (UFF) e Universidade Federal de Minas Gerais (UFMG). Na UNICAMP, no Instituto de Química, destaca-se o grupo liderado por Pedro F. dos Santos Filho e, na Faculdade de Educação, o grupo liderado por Maria Inês P. Rosa $(22,97$ e 8,11\%, respectivamente, dos 74 trabalhos apresentados pela instituição). Na UFF, o grupo liderado por Lucidea G. R. Coutinho, do Instituto de Química, contribuiu com $24,24 \%$ dos 66 trabalhos apresentados pela instituição. Na UFMG, na Faculdade de Educação, destaca-se o grupo liderado por Eduardo F. Mortimer e, no Departamento de Química, o grupo liderado por Ana Luiza de Quadros (22,41 e 10,34\%, respectivamente, dos 58 trabalhos apresentados pela instituição).

Analisando a produção das IES da região Nordeste, destacam-se a Universidade Federal Rural de Pernambuco (UFRPE) e a Universidade Federal de Sergipe (UFS). Os grupos de pesquisa que contribuíram fortemente para esta produção são liderados por Rejane M. N. Barbosa (47,62\% dos 42 trabalhos apresentados pela UFRPE) e por Djalma Andrade (62,06\% dos 29 trabalhos apresentados pela UFS). Ambas atuam nos Departamentos de Química das respectivas instituições.

Na região Centro-oeste, encontramos a Universidade de Brasília (UnB) e a Universidade Federal de Goiás (UFG) como as IES de maior atividade na área. A maioria dos trabalhos apresentados pela UnB foi produzida no grupo liderado por Roberto R. da Silva (29,79\% do total de 47 trabalhos apresentados pela instituição) e na UFG no grupo liderado por Márlon H. F. B. Soares (55,55 \% dos 27 trabalhos apresentados pela instituição), ambos vinculados a Institutos de Química. Na região Sul, destaca-se a Universidade Estadual de Londrina (UEL). Nesta Instituição o grupo liderado por Eliana S. Bueno, do Departamento de Química, produziu 80\% dos 20 trabalhos apresentados nas RASBQs em questão.

A consulta dos currículos dos líderes dos grupos acima mencionados junto à plataforma Lattes ${ }^{9}$ indica que a maioria ( 9 docentes) vem atuando nos últimos anos como orientador de dissertações de mestrado e/ou de teses de doutorado exclusivamente sobre a temática da Educação em Química. Em contrapartida, 2 docentes orientam trabalhos quase que exclusivamente na área de Química, enquanto 3 docentes não atuam em programas de pós-graduação, mas se dedicam à orientação de alunos de iniciação científica e/ou de monografias de conclusão de curso exclusivamente sobre a temática da Educação em Química. Este quadro sugere a participação, na seção de Ensino de Química, de uma comunidade formada, principalmente, por pesquisadores da área de Educação em Química e por pesquisadores da área de Química que, assim como definem Bejarano e Carvalho, ${ }^{3}$ gostam da "causa da educação" e acabam enviando trabalhos para as RASBQs. Professores do ensino médio e alunos de iniciação científica e de pós-graduação também apresentam trabalhos, usualmente em parceria como os seus orientadores, sejam eles pesquisadores da área de Educação em Química ou Química.

\section{A produção e sua distribuição de acordo com os níveis de escolaridade}

A identificação do nível escolar ao qual se relacionam os resumos fez-se possível por meio da utilização dos descritores sobre níveis escolares estabelecidos por Megid Neto. ${ }^{5}$ Alguns dos elementos considerados para a identificação do nível escolar foram: os sujeitos participantes na pesquisa, os materiais didáticos avaliados, os programas de ensino propostos e as experiências educacionais relatadas 
na pesquisa. Acreditando que a identificação de tais elementos não seria possível apenas a partir da leitura do resumo, que se encontra disponível nos livros de resumos das RASBQs editados de 2001 até 2005, devido ao conteúdo extremamente restrito aí apresentado, estabelecemos que a classificação quanto ao nível de escolaridade somente seria realizada para os resumos apresentados nos Livros de Resumos das Reuniões ocorridas em 1999 e 2000 e para os trabalhos que se encontrassem disponíveis no site da SBQ, a partir de 2001. Conforme mencionamos anteriormente, o formato destes resumos permitia ao autor a apresentação de um trabalho com um número considerável de informações. Faz-se necessário relembrar que 52 trabalhos, dos 1008 pertencentes à seção de ED, não foram contabilizados por serem procedentes exclusivamente do exterior; os trabalhos ED-022(1999) e ED-092(2005) também não foram contabilizados por razões já mencionadas; 148 outros trabalhos também não o foram, porque não estavam disponíveis para leitura no site da SBQ até o dia 12/12/2006, data da finalização da coleta dos nossos dados. São eles: 26 trabalhos da reunião de 2002; 8 trabalhos da de 2003; 6 trabalhos da de 2004; todos os 108 trabalhos da de 2001. Assim, para as análises dos percentuais de representatividade quanto aos níveis de escolaridade, utilizamos como base para cálculo 806 trabalhos. Destes trabalhos, 114 foram classificados em 2 ou em 3 níveis de escolaridade. Por esta razão, o número de trabalhos apresentados na Tabela 3 é 927 e não mais os 806 mencionados anteriormente. Cabe ainda ressaltar que entre todos os trabalhos em estudo, nenhum deles foi destinado ao Ensino Infantil.

Considerando os dados apresentados na Tabela 3, constatamos que a maior porcentagem de trabalhos da seção de ED é dedicada ao Ensino Médio (53,60\%), seguida por trabalhos voltados ao Ensino Superior $(42,92 \%)$ e Ensino Fundamental (8,44\%). A baixa porcentagem de trabalhos voltados ao Ensino Fundamental pode estar associada ao fato da introdução de tópicos relacionados à Química ocorrer, de forma mais efetiva, apenas nas últimas etapas deste nível escolar $\left(7^{\mathrm{a}}\right.$ e $8^{a}$ séries). De fato, a grande maioria dos trabalhos apresentados na seção de ED voltados para o Ensino Fundamental trata de propostas de aplicação de projetos e de desenvolvimento de materiais didáticos. Algumas pesquisas dedicadas a estas séries tratam também da identificação de concepções dos alunos e das suas dificuldades na compreensão de alguns conceitos. Em número menor encontram-se os trabalhos de caráter mais abrangente, que abarcam todas as séries do Ensino Fundamental, e os trabalhos que relatam experiências sobre a capacitação de professores deste nível de ensino.

Quanto à alta taxa de produção em relação aos trabalhos voltados para o Ensino Médio, esta pode estar relacionada ao fato do ensino de Química atravessar todas as séries deste nível de ensino. Os assuntos abordados nos trabalhos relacionados ao Ensino Médio são variados, existindo a preocupação no que diz respeito à elaboração e aplicação de diversos materiais didáticos com o intuito de facilitar o processo de ensino-aprendizagem de conceitos químicos. A análise de livros didáticos adotados neste nível de escolaridade e a reflexão sobre as políticas educacionais para o Ensino Médio (especialmente os Parâmetros Curriculares Nacionais para o Ensino Médio - PCNEM), além do desenvolvimento e aplicação de novas metodologias de ensino, são preocupações que estão presentes nos trabalhos.
Destaca-se, em seguida, a produção de trabalhos relacionados ao Ensino Superior. Alguns dos assuntos abordados nos trabalhos voltados a este nível de ensino são: apresentação de propostas para melhoria da aprendizagem dos alunos a partir da utilização dos mais variados recursos didáticos, com destaque para materiais didáticos que encontram uso em laboratórios de ensino; descrição de programas que almejam a aproximação da Universidade com a Escola e com a Indústria, bem como a integração do ensino de graduação com o de pós-graduação; identificação de concepções de estudantes e professores sobre assuntos variados; elaboração e/ou aplicação de atividades teóricas e experimentais desenvolvidas por alunos de Licenciatura dentro de disciplinas pedagógicas.

Os trabalhos classificados no descritor Geral, relativo aos estudos que abordam os vários níveis escolares de forma genérica ou não particular, são representativos dentro do montante total $(10,04 \%)$ e ultrapassam o número dedicado ao Ensino Fundamental. Estes são muito distintos entre si, podendo-se, no entanto, apontar 2 tendências que são detectadas com maior frequiência nos trabalhos incluídos nesta classificação. A primeira delas se relaciona às tecnologias educacionais e engloba trabalhos que relatam a criação de softwares e sites educacionais voltados para o ensino de Química, sem especificar o nível escolar dos alunos que pretendem atingir, e que podem ser de interesse do público em geral. A outra tendência está relacionada à Educação Ambiental e abarca trabalhos que tratam de conscientização do cidadão com relação ao seu papel na comunidade. Estes estudos relatados têm como alvo um número considerável de pessoas, como por exemplo, todos os membros de uma escola ou de uma comunidade de determinada localidade.

\section{A produção e sua distribuição de acordo com o gênero de trabalho acadêmico e foco temático}

Classificamos os resumos apresentados na seção de ED das RASBQs, no período de 1999 a 2006, de acordo com o gênero de trabalho e com o foco temático. Nesta perspectiva, diferenciamos os trabalhos por nós analisados em 2 grupos: o primeiro inclui trabalhos de investigação/pesquisa e o segundo, trabalhos que descrevem inovações pedagógicas e relatos de experiência. Para a classificação dos focos, tomamos por base os descritores específicos utilizados por Megid Neto, ${ }^{5}$ que se encontram listados a seguir:

Currículos e Programas - estudos dos princípios, parâmetros, diretrizes e fundamentos teórico-metodológicos para o ensino de ciências, contemplando as diversas etapas atribuídas à grade curricular (objetivos educacionais, conteúdos, estratégias, avaliações etc.). Discussão do papel da escola, das relações entre ciência e sociedade e outros aspectos do sistema educacional. Avaliação de propostas curriculares ou projetos educacionais. Proposição e desenvolvimento de programas ou propostas alternativas de ensino para uma série, disciplina, semestre letivo ou ciclo escolar completo. Conteúdo-Método - trabalhos que analisam a relação conteúdo-método no ensino de ciências, com foco de atenção no conhecimento científico veiculado na escola, na forma

Tabela 3. Distribuição dos trabalhos na seção de ED nas RASBQs de acordo com o nível escolar abrangido no período de 1999 a 2006

\begin{tabular}{lcccccccrrrr}
\hline Nível escolar & 1999 & 2000 & 2001 & 2002 & 2003 & 2004 & 2005 & 2006 & Total & $\%$ \\
\hline Ensino Fundamental & 17 & 11 & - & 03 & 07 & 11 & 10 & 09 & 68 & 8,44 \\
Ensino Médio & 54 & 50 & - & 44 & 71 & 59 & 91 & 63 & 432 & 53,60 \\
Ensino Superior & 23 & 38 & - & 32 & 52 & 64 & 72 & 65 & 346 & 42,92 \\
Geral & 07 & 05 & - & 08 & 14 & 21 & 15 & 11 & 81 & 10,04 \\
\hline
\end{tabular}


como este conhecimento é difundido por meio de métodos e técnicas de ensino-aprendizagem, ou ainda na perspectiva de indissociação entre forma e conteúdo. Estudos a respeito da aplicação de métodos e técnicas no ensino de ciências, como instrução programada, courseware, módulos de ensino, experimentação, dramatização, entre outros, de forma isolada ou comparativa. Trabalhos que propõem método alternativo para o ensino de ciências ou que descrevem e avaliam práticas pedagógicas e a metodologia de ensino neles presente.

Recursos Didáticos - estudos de avaliação de materiais ou recursos didáticos no ensino de ciências, como textos de leitura, livros didáticos, materiais de laboratório, filmes, computador, jogos, mapas conceituais entre outros. Trabalhos que propõem elou aplicam e avaliam novos materiais, kits experimentais, softwares ou outros recursos e meios instrucionais em situações de ensino formal ou extracurricular.

Características do Professor - diagnóstico das condições profissionais do professor da área de Ciências. Identificação do perfil sociográfico do professor, de sua estrutura intelectual, de seu conhecimento 'espontâneo', de suas concepções sobre ciência, métodos de produção científica, educação, ambiente, saúde, sexualidade etc. Diagnóstico da prática pedagógica de um professor ou grupo de professores, explicitando suas idiossincrasias e concepções do processo educacional.

Características do Aluno - diagnóstico das condições socioeconômicas e culturais dos alunos e suas implicações no rendimento escolar ou aprendizagem em ciências. Identificação ou constatação do conhecimento prévio do aluno, de sua estrutura intelectual, modelos de pensamento ou de suas idéias sobre ciência, métodos de produção científica, ambiente, saúde, sexualidade etc. Estudos das atitudes e características de um aluno ou grupo de alunos no contexto do processo de ensino-aprendizagem.

Formação de Conceitos - trabalhos que descrevem e analisam o desenvolvimento de conceitos científicos no pensamento dos alunos elou professores, implicando em processos de mudança ou evolução conceitual. Comparação de modelos de pensamento com modelos conceituais presentes na História da Ciência. Estudos sobre a relação entre estrutura cognitiva de estudantes e o processo ensino-aprendizagem de conceitos científicos em processos formais ou não-formais de ensino. Relação entre modelos de pensamento ou faixa etária ou nível de escolaridade dos indivíduos.

Formação de Professores - trabalhos relacionados com a formação inicial de professores para o ensino na área de Ciências Naturais, no âmbito da Licenciatura, da Pedagogia ou do Ensino Médio - modalidade normal (antigo Magistério). Estudos de avaliação ou propostas de reformulação de cursos de formação inicial de professores. Estudos voltados para a formação continuada ou permanente dos professores da área de Ciências, envolvendo propostas elou avaliação de programas de aperfeiçoamento, atualização, capacitação, treinamento ou especialização de professores. Descrição e avaliação da prática pedagógica em processos de formação em serviço.

Políticas Públicas - programas, diretrizes, ações, objetivos e interesses de um indivíduo ou grupo, governamental ou não, voltados para o público em geral e relacionados com um único conjunto de problemas da coletividade, desde que explicitadas suas repercussões ou ligações com a educação científica.
Organização da Escola - diagnóstico das características de instituições escolares da educação básica ou superior, abrangendo aspectos relativos à gestão escolar, nos seus aspectos político-administrativos, pedagógico, funcional, físico entre outros. Estudos das relações entre os diversos segmentos escolares e da escola com a comunidade.

Programa de Ensino Não-Escolar - estudos com foco de atenção na organização de instituições não-escolares ou nãoformais de ensino, como organizações não-governamentais (ONGs), Secretarias de Meio Ambiente, de Saúde, de Cultura, Museus, Clubes ou Centros de Ciências, Mostras, Feiras ou Exposições Científicas. Programas de educação ambiental, de higiene e saúde ou de educação sexual realizados junto à comunidade. Programas de formação continuada de professores executados por instituições educacionais nãoescolares (por exemplo, Centro de Ciências). Programas de atividades extracurriculares para alunos efetuados em espaços não-formais de ensino, como por exemplo, em Museus de Ciências.

Filosofia da Ciência - aspectos relativos à filosofia ou epistemologia da ciência, tais como concepção de ciência, de cientista, de método científico, formulação e desenvolvimento de teorias científicas, paradigmas e modelos científicos e suas implicações no ensino quanto à formulação de currículos, $e$ de formação de professores, ao desenvolvimento de programas de ensino-aprendizagem entre outros.

História da Ciência - estudos de revisão bibliográfica em fontes primárias e secundárias que resgatam acontecimentos, fatos, debates, conflitos e circunstâncias da produção científica em determinada época do passado próximo ou remoto, $e$ as articulações entre eles. Necessariamente, esses estudos devem explicitar alguma relação com o ensino na área de Ciências como: fundamentação de currículos, programas de formação de professores, concepções 'espontâneas' dos estudantes e outras implicações para o processo de ensinoaprendizagem.

História do Ensino de Ciências - pesquisas de caráter histórico sobre a evolução do ensino de ciências no Brasil ou sobre características isoladas desse ensino (materiais didáticos, currículos, legislação, formação de professores etc.), abrangendo determinada época do passado.

Outro - foco particular que não encontra correspondência com os demais, cuja incidência de casos no conjunto dos documentos classificados é bastante pequena. Incluem-se estudos sobre exames vestibulares, pesquisas do tipo estado da arte sobre a produção acadêmica e científica, entre outros temas presentes nos documentos em estudo sobre o ensino de ciências.

No que diz respeito aos focos Conteúdo-Método e Recursos Didáticos, adaptamos a descrição de Megid Neto, ${ }^{5}$ com o intuito de distinguir um foco do outro de forma mais clara. Assim, trabalhos que apresentam apenas a descrição de um recurso didático ou de um procedimento experimental foram classificados no foco Recursos Didáticos. Em contrapartida, trabalhos que apresentam, além da descrição do recurso didático ou do procedimento experimental, uma avaliação a respeito do papel por eles desempenhado no processo de ensinoaprendizagem foram classificados no foco Conteúdo-Método.

Outro foco digno de nota é o de Formação de Professores. Encontramos dificuldades em fazer a classificação dos trabalhos abarcados por este foco, quanto ao nível de escolaridade ao qual se destinavam. Após uma análise cuidadosa, optamos por adotar o parâmetro de classificação descrito a seguir. Dividimos o foco temático 
Formação de Professores em 2 outros focos: Formação Continuada de Professores e Formação Inicial de Professores. Os trabalhos sobre Formação Continuada de Professores foram classificados, quanto ao nível de escolaridade, em Ensino Fundamental ou Médio, uma vez que se relacionam às atividades de professores atuantes nestes níveis de escolaridade (professores de Ciências do Ensino Fundamental e/ou professores de Química no Ensino Médio). Trabalhos que tratam da Formação Inicial de Professores foram classificados, quanto ao nível de escolaridade, em Ensino Superior, uma vez que se relacionam a atividades de licenciandos.

Analisamos 806 trabalhos, dentre os 1008 apresentados na seção de ED das RASBQs no período em estudo. Foram excluídos da análise os mesmos trabalhos mencionados no tópico anterior, pelas razões já explicitadas. Cada trabalho foi classificado em um ou mais focos temáticos, de acordo com o conteúdo abordado. Na maioria dos trabalhos em que detectamos mais de um foco temático, assumimos como foco temático principal do trabalho o tema privilegiado no estudo e como foco temático secundário aquele menos explorado no desenvolvimento da pesquisa. No entanto, durante a nossa análise, nos deparamos também com alguns trabalhos que possuíam mais do que um foco temático e nos quais ambos os focos possuíam a mesma relevância. Assim, os trabalhos com mais de um foco temático foram classificados como possuindo 2 focos temáticos principais ou como possuindo um foco temático principal e um foco temático secundário. Considerando que 701 trabalhos apresentaram somente 1 foco; 100 apresentaram 2 focos temáticos e 5 apresentaram 3 focos temáticos, o total contabilizado foi de 806 trabalhos. Todos os percentuais apresentados na Figura 3, que ilustra a porcentagem de trabalhos relacionados a cada um dos focos, foram calculados sobre 806 trabalhos.

Tendo em vista a inviabilidade de discussão de cada um dos trabalhos apresentados, optamos por apresentar, a seguir, as principais características e gênero de pesquisa dos trabalhos classificados em cada um dos focos. Cabe destacar que para a realização da análise foram considerados apenas os focos temáticos principais dos trabalhos.

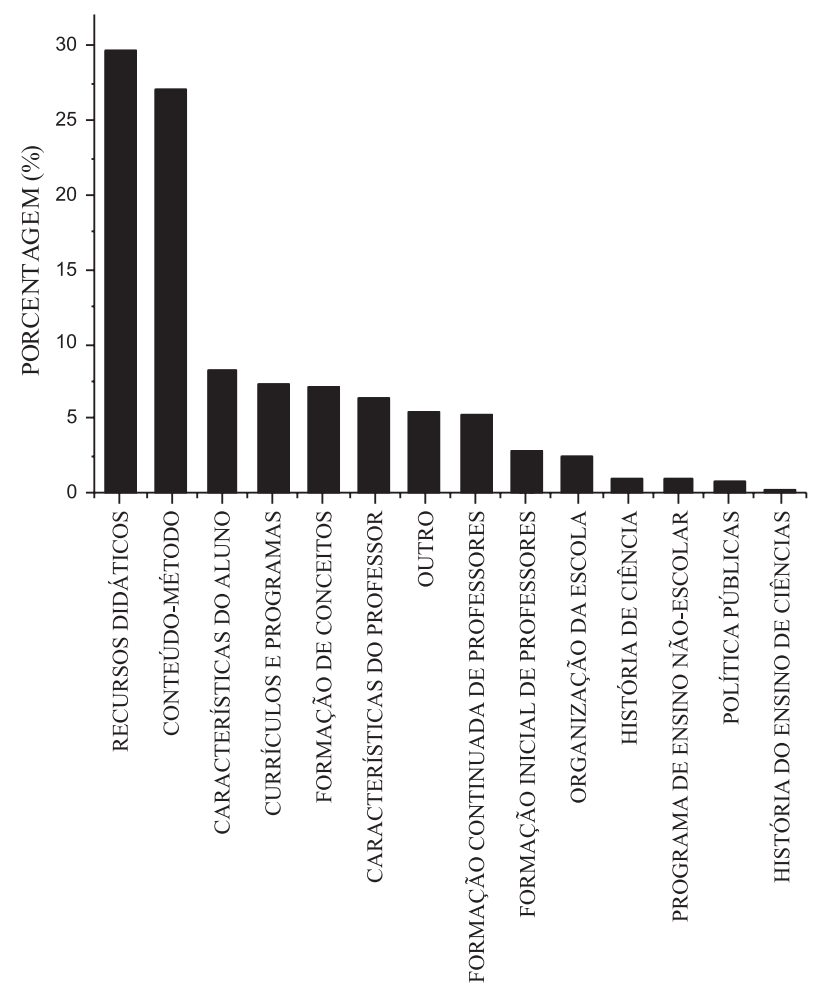

Figura 3. Distribuição dos trabalhos de acordo com o foco temático apresentado na seção de ED nas RASBQS no período de 1999 a 2006
Ou seja, para o caso de trabalhos que apresentaram um foco temático principal e um foco temático secundário, este último foi desconsiderado na análise. Os focos são discutidos em ordem decrescente do número de trabalhos neles classificados.

\section{Recursos didáticos}

Foram identificados 239 trabalhos neste foco temático, 45 classificados como trabalhos de pesquisa/investigação e os demais como descrições de inovações pedagógicas e relatos de experiência. $\mathrm{O}$ Ensino Superior foi o nível de escolaridade privilegiado neste foco, seguido pelo Ensino Médio, e nos trabalhos nele classificados estão presentes, principalmente, propostas de atividades de ensino que se baseiam na utilização de experimentos de laboratório (133 trabalhos), novas tecnologias educacionais (28 trabalhos), modelos moleculares (5 trabalhos), jogos (3 trabalhos), vídeos (7 trabalhos), textos (3 trabalhos), entre outras. A grande quantidade de trabalhos relacionados à proposição/aplicação de técnicas e materiais diversificados em laboratórios didáticos (mais da metade dos trabalhos classificados neste foco) não é surpreendente, uma vez que a Química é um ramo das Ciências Naturais que possui como uma de suas características a atividade experimental.

Também neste foco temático foram classificados 36 trabalhos que investigam aspectos relacionados à análise de livros didáticos de Química: 27 tratam de livros didáticos utilizados no Ensino Médio, 4 no Ensino Fundamental, 4 no Ensino Superior e 1 de caráter geral. As análises são realizadas visando a compreensão de questões como: a representação estrutural de moléculas orgânicas nos livros de Química de volume único no Ensino Médio; o uso de um determinado livro em sala de aula (Química e Sociedade ${ }^{10}$ ); a reação de "dupla troca" e o seu significado nos livros didáticos de Química no Ensino Médio; a contextualização dos termos ionização e dissociação nos livros didáticos; a forma como a Química Orgânica é apresentada nos livros didáticos, no que concerne à apresentação e inclusão de aspectos da História da Ciência. Cabe destacar que grande parte dos trabalhos de pesquisa/ investigação classificados neste foco diz respeito à investigação de livros didáticos (34 em um total de 45 trabalhos).

\section{Conteúdo-método}

Foram identificados 218 trabalhos neste foco temático, 78 classificados como trabalhos de pesquisa/investigação e os demais como descrições de inovações pedagógicas e relatos de experiência. A maior parte dos trabalhos é destinada ao Ensino Médio (105 trabalhos), seguido pelo Ensino Superior (58 trabalhos) e Fundamental (12 trabalhos). Neles são, principalmente, propostas e analisadas atividades de ensino que se baseiam na utilização de experimentos de laboratório (28 trabalhos), novas tecnologias educacionais (16 trabalhos), atividades lúdicas (9 trabalhos), entre outras.

Neste foco são ainda dignos de nota os trabalhos que sugerem e avaliam os resultados da introdução de conteúdos químicos, levando em conta tanto a questão da contextualização, quanto da interdisciplinaridade (a palavra interdisciplinaridade e palavras a ela relacionada, como multidisciplinaridade, estão presentes no título de 15 trabalhos), podendo-se citar como exemplo os trabalhos apresentados pelo GIPEC-UNIJUI, ${ }^{11}$ que propõem o desenvolvimento de Situações de Estudo como novo enfoque curricular, tanto disciplinar quanto interdisciplinar.

Trabalhos que trazem em seu bojo a preocupação com a aplicação e a avaliação de propostas de ensino voltadas para deficientes visuais foram também incluídos neste foco.

\section{Características do aluno}

Foram identificados 67 trabalhos neste foco temático, 66 classificados como trabalhos de pesquisa/investigação e apenas 1 como 
relato de experiência. A maioria dos trabalhos procura caracterizar os conhecimentos prévios dos alunos sobre conceitos científicos (16 trabalhos), as suas idéias e opiniões sobre assuntos variados, relacionados, ou não, ao processo de ensino-aprendizagem (34 trabalhos) e o entendimento que possuem sobre a forma como a Ciência é construída e sobre o papel do trabalho experimental na Química (6 trabalhos). A quantidade de trabalhos destinada ao Ensino Médio (26 trabalhos) é semelhante àquela destinada ao Ensino Superior (28 trabalhos).

\section{Currículos e programas}

Foram identificados 59 trabalhos neste foco temático, 32 classificados como trabalhos de pesquisa/investigação e 27 como relato de experiência. Quase a metade dos trabalhos se destina ao Ensino Superior (28 trabalhos) e trata, via de regra, da introdução de novas disciplinas no currículo vigente de algumas IES ou da reestruturação de disciplinas já em vigência no curso. Exemplos de trabalhos deste tipo são aqueles que relatam uma nova abordagem da disciplina "Química Fundamental" do curso de Química da UNESP e a análise da disciplina "Atividades Acadêmicas Científico e Culturais" implantada na Licenciatura em Química do Instituto de Química da USP.

Trabalhos que discutem a implementação de programas educacionais visando uma maior integração entre a Universidade e a Escola Básica e os que se dedicam a investigar os Parâmetros Curriculares Nacionais (PCN) e a sua repercussão nos ambientes de ensino também foram incluídos neste foco.

\section{Formação de conceitos}

Foram identificados 58 trabalhos neste foco temático, 54 classificados como trabalhos de pesquisa/investigação e os demais como relatos de experiência. A descrição de investigações a respeito do desenvolvimento de conceitos de alunos e professores, que implicaram em um processo de mudança e/ou evolução conceitual, é uma característica comum a 30 trabalhos nele classificados. Neste contexto, a descrição da realização de pré-testes e pós-testes com o intuito de avaliação da ocorrência, ou não, de mudança e/ou evolução conceitual durante o processo de ensino-aprendizagem está presente em aproximadamente um terço dos referidos trabalhos.

Trabalhos que estabelecem comparações entre o entendimento de conceitos químicos por indivíduos de diferentes níveis de escolaridade também foram incluídos, assim como aqueles que se preocupam em avaliar o uso de determinadas estratégias como ferramenta no processo de construção de conceitos pelo aluno.

A maior parte dos trabalhos deste foco são destinados ao Ensino Médio (33 trabalhos), seguido pelo Ensino Fundamental (9 trabalhos) e Superior ( 6 trabalhos).

\section{Características do professor}

Foram identificados 52 trabalhos neste foco, 51 classificados como trabalhos de pesquisa/investigação e apenas 1 como relato de experiência. Características de professores exclusivamente do Ensino Médio foram investigadas em 33 trabalhos e exclusivamente do Ensino Superior em 8 trabalhos. Em um total de 10 trabalhos foram investigadas características de professores de mais de um nível de ensino, incluindo o Ensino Fundamental. Dentre as características investigadas destacam-se aquelas relacionadas: às práticas pedagógicas adotadas pelos docentes (16 trabalhos), às suas concepções/ entendimento sobre determinados conceitos científicos (6 trabalhos) e sobre o papel da experimentação no ensino de Química (4 trabalhos). Trabalhos que traçam o perfil dos docentes e do ensino de Química de determinadas regiões, como Ilhéus, Goiás, São João del Rei, entre outras, também foram relatados com frequiência (7 trabalhos).

Os demais trabalhos tratam de outras características dos professores, que não as mencionadas anteriormente, que incluem os seus diferentes estilos de ensinar e as suas percepções e impressões quanto à incorporação do computador no rol de ferramentas para utilização pedagógica. Cabe destacar que 14 trabalhos classificados neste foco se ocupam de investigar também as características dos alunos. Assim, foram igualmente alocados no foco Características do Aluno.

\section{Outro}

Neste foco foram alocados 44 trabalhos que não encontram correspondência com os demais e/ou cuja incidência de casos no conjunto de documentos classificados é pequena. Deste total, 31 foram classificados como trabalhos de pesquisa/investigação e os demais como relatos de experiência. Dentre eles destacam-se 8 trabalhos relacionados a exames vestibulares e 10 relacionados à linguagem e cognição. Nos primeiros são realizadas análises de provas e de conhecimentos químicos exigidos nas questões dos vestibulares da Universidade Federal do Rio de Janeiro (UFRJ), Universidade Estadual do Sudoeste da Bahia (UESB), Universidade Estadual Paulista (UNESP) e Universidade Estadual de Campinas (UNICAMP), existindo uma concentração de trabalhos no que diz respeito a esta última (5 trabalhos). Os trabalhos relacionados à linguagem e cognição enfatizam, entre outros aspectos, a importância das interações discursivas e da linguagem em sala de aula e no processo de elaboração conceitual em Química.

Trabalhos de revisão bibliográfica e aqueles relacionados à formação de mestres e doutores titulados no Brasil também foram alocados neste foco.

\section{Formação continuada de professores}

Foram identificados 43 trabalhos neste foco, 26 classificados como trabalhos de pesquisa/investigação e os demais como relatos de experiência. Em 32 trabalhos foram discutidos aspectos concernentes exclusivamente à formação de professores do Ensino Médio, em 4 trabalhos exclusivamente à formação de professores do Ensino Fundamental e em 3 trabalhos à formação de professores dos 2 níveis de ensino. Nenhum trabalho relacionado à formação de professores do Ensino Superior foi localizado.

Neste foco destacam-se 14 trabalhos, originários de várias regiões do país, que tratam de atividades realizadas no âmbito dos Programas de Formação de Professores Pró-Ciências ${ }^{12}$ e Teia do Saber ${ }^{13}$ e reflexões delas advindas. Trabalhos de mesma natureza, porém não vinculados aos referidos Programas são numerosos (20 trabalhos). Dentre os quais se destaca o projeto de formação de professores envolvendo docentes do Departamento de Física e Química da UNESP de Ilha Solteira e da Escola Estadual de Urubupungá, cujas ações dele resultantes foram relatadas com frequiência nas RASBQs, 4 trabalhos apresentados no intervalo de 2003 a 2006.

Trabalhos que discutem questões que associam as tecnologias digitais à formação docente também foram classificados neste foco.

\section{Formação inicial de professores}

Foram identificados 23 trabalhos neste foco, 17 classificados como trabalhos de pesquisa/investigação e os demais como relatos de experiência. Uma vez que 10 trabalhos dizem respeito exclusivamente ao Ensino Superior e 8 ao Ensino Superior e Médio, o nível escolar privilegiado neste foco foi o Ensino Superior. Um número considerável de trabalhos, 14 no total, relata a elaboração por parte de licenciandos de material instrucional ou de estratégias de ensino, que, em alguns casos, são utilizados por eles mesmos, na prática de ensino em escolas do nível médio ou em atividades dirigidas ao público em geral. Nesta perspectiva, tais materiais e estratégias são desenvolvidos, via de regra, no âmbito de disciplinas pedagógicas como Didática e Prática de Ensino de Química, Estágio em Ensino de Química, Instrumentação para o Ensino de Química, entre outras, em várias universidades do país. 
Também é significativa a quantidade de trabalhos ( 7 trabalhos) que trata de identificar as idéias dos licenciandos sobre aspectos relacionados à docência, como o uso de analogias no processo de ensino-aprendizagem de Química e sobre o ensino experimental no ensino médio desta disciplina. Trabalhos desta natureza são também incluídos no foco Características do Professor. Os demais trabalhos abordam temáticas variadas que incluem a análise das monografias de conclusão de curso dos alunos de Licenciatura em Química da Universidade de Brasília no período de 1996 a 2001 e a investigação de constituição da autonomia do professor de Química.

\section{Organização da escola}

Foram identificados 20 resumos neste foco, 9 classificados como trabalhos de pesquisa/investigação e os demais como relatos de experiência. Mais da metade, 16 trabalhos, é relacionada ao Ensino Superior e os demais, ao Ensino Médio. Dentre os trabalhos voltados ao Ensino Superior destacam-se aqueles que tratam do gerenciamento de resíduos gerados em laboratórios didáticos (5 trabalhos) e da evasão escolar (4 trabalhos). A Universidade Estadual de Campinas (UNICAMP), Universidade Federal do Ceará (UFC), UNIVATES Centro Universitário e Universidade Presbiteriana Mackenzie são instituições mencionadas em trabalhos que se relacionam ao gerenciamento de resíduos, enquanto a Universidade Federal Rural do Rio de Janeiro (UFRRJ), Universidade Estadual de Maringá (UEM), Universidade Estadual do Sudoeste da Bahia (UESB) e Universidade Federal de Minas Gerais (UFMG) são mencionadas em trabalhos que tratam da evasão escolar. Neste nível de ensino também se encontram trabalhos que tratam do acompanhamento de egressos dos cursos de graduação e de aspectos relacionados à forma como a segurança em laboratórios é abordada no contexto das disciplinas.

Assim como nos trabalhos destinados ao Ensino Superior, grande parte daqueles direcionados ao Ensino Médio discute questões concernentes à redução de resíduos gerados nas escolas, tanto nas aulas práticas quanto nas atividades do dia-a-dia.

\section{História da Ciência}

Foram identificados 8 resumos neste foco, 5 classificados como trabalhos de pesquisa/investigação e os demais como relatos de experiência. A contextualização histórica de determinados conteúdos de Química (como gases e compostos de coordenação) é relatada em 6 trabalhos, que visam uma melhor compreensão por parte dos alunos, tanto dos referidos conteúdos, quanto da construção do conhecimento científico. Os outros trabalhos investigam como a História da Ciência pode auxiliar a compreensão da teoria atômica de Dalton e propõem um novo enfoque didático para a Lei de Dalton das pressões parciais.

\section{Programa de ensino não-escolar}

Foram identificados 8 resumos neste foco, 3 classificados como trabalhos de pesquisa/investigação e os demais como relatos de experiência. Atividades oferecidas ao público em espaços nãoformais de ensino, com o intuito de relacionar aspectos lúdicos com o aprendizado de Química e de mostrar a "química do dia-a-dia" a partir de situações concretas, foram mencionadas em 6 trabalhos. A Casa da Descoberta, da Universidade Federal Fluminense, o Jardim Zoológico do Rio de Janeiro, e o bairro de Vista Alegre, no Rio de Janeiro, são exemplos de tais espaços.

Incluídos no foco temático em questão estão ainda 2 trabalhos que tratam de programa de formação científico-tecnológica, dirigido aos trabalhadores de empresa do Grupo Siemens, e de iniciativas do Parque da Ciência Museu da Vida (Fiocruz) visando aferir a "aceitação" de visitantes em relação a uma atividade de modelagem molecular, elaborada a partir da utilização de materiais de fácil acesso, como argila e palito.

Todos os trabalhos alocados neste foco foram classificados no nível de escolaridade Geral, uma vez que procuram atingir um público amplo e não apenas estudantes de um determinado nível de ensino. Mais da metade deles ( 6 trabalhos) foram apresentados recentemente, no intervalo de 2003 a 2006.

\section{Políticas públicas}

Foram identificados 6 resumos neste foco, 2 classificados como trabalhos de pesquisa e os demais como relatos de experiência. Questões relacionadas à Educação Ambiental são abordadas em 3 trabalhos, que visam a sensibilização, compreensão e responsabilidade do cidadão frente à coleta seletiva de lixo e à utilização, reciclagem e descarte de alumínio, plásticos e embalagens descartáveis. Os demais trabalhos tratam de assuntos que incluem os avanços no ensino de Química dirigido a deficientes visuais, a articulação coletiva de esforços para o ensino de graduação nas universidades públicas paulistas e o estabelecimento de um paralelo entre a formação do profissional em Química e o perfil esperado pelas empresas.

\section{História do Ensino de Ciências}

Os 2 resumos identificados neste foco foram classificados como trabalhos de pesquisa. O primeiro investiga, através da análise dos livros didáticos de Química escritos por brasileiros e utilizados nos níveis médio e superior no final do século XIX e início do século XX, como se deu a recepção da Tabela Periódica dos Elementos no Brasil. O segundo trata das realizações do Prof, Reinaldo C. Silva, considerado pelos autores do trabalho como um pioneiro no ensino de Química.

\section{Filosofia da Ciência}

Não foram identificados trabalhos que apresentassem como foco principal a Filosofia da Ciência. Apenas 3 resumos apresentaram como foco secundário a Filosofia da Ciência, todos classificados como trabalhos de pesquisa. O primeiro, cujo foco principal é Formação de Conceitos, investiga a evolução conceitual de alunos do Ensino Médio a respeito de modelos atômicos, após intervenções didáticas utilizando metodologias diferenciadas, sendo que uma delas foi idealizada a partir de considerações pautadas na História e na Filosofia da Ciência. O segundo, cujo foco principal é Características do Aluno, analisa as concepções de Ciência e de trabalho experimental de graduandos em Química da Universidade Federal de Pelotas (UFPel). O terceiro, cujo foco principal é Recursos Didáticos, analisa nos livros didáticos do Ensino Médio, como o conhecimento científico, dentro do tema de cinética química, é apresentado aos alunos no decorrer do tempo. $\mathrm{O}$ modelo adotado para a análise considera as idéias de Lakatos sobre a natureza e a construção do conhecimento científico

A partir da análise da Figura 4, que mostra o número de trabalhos, em cada foco temático, classificados como trabalhos de pesquisa/ investigação e como descrições de inovações pedagógicas e relatos de experiência, faz-se possível perceber que o perfil diferenciado dos participantes das RASBQs (principalmente pesquisadores da área de Educação em Química e pesquisadores da área de Química que gostam da "causa da educação", como mencionamos anteriormente) se reflete no gênero dos trabalhos. De fato, trabalhos de pesquisa/ investigação concentram-se fortemente nos focos Características do Aluno, Formação de Conceitos, Características do Professor e Formação de Professores, que podem ser relacionados a linhas de pesquisas consolidadas na área de Educação em Química no Brasil. Em contrapartida, a forte concentração de descrições de inovações pedagógicas e de relatos de experiência nos focos Recursos Didáticos e Conteúdo-Método se deve, provavelmente, em grande parte, às colaborações advindas dos pesquisadores da área de Química. 


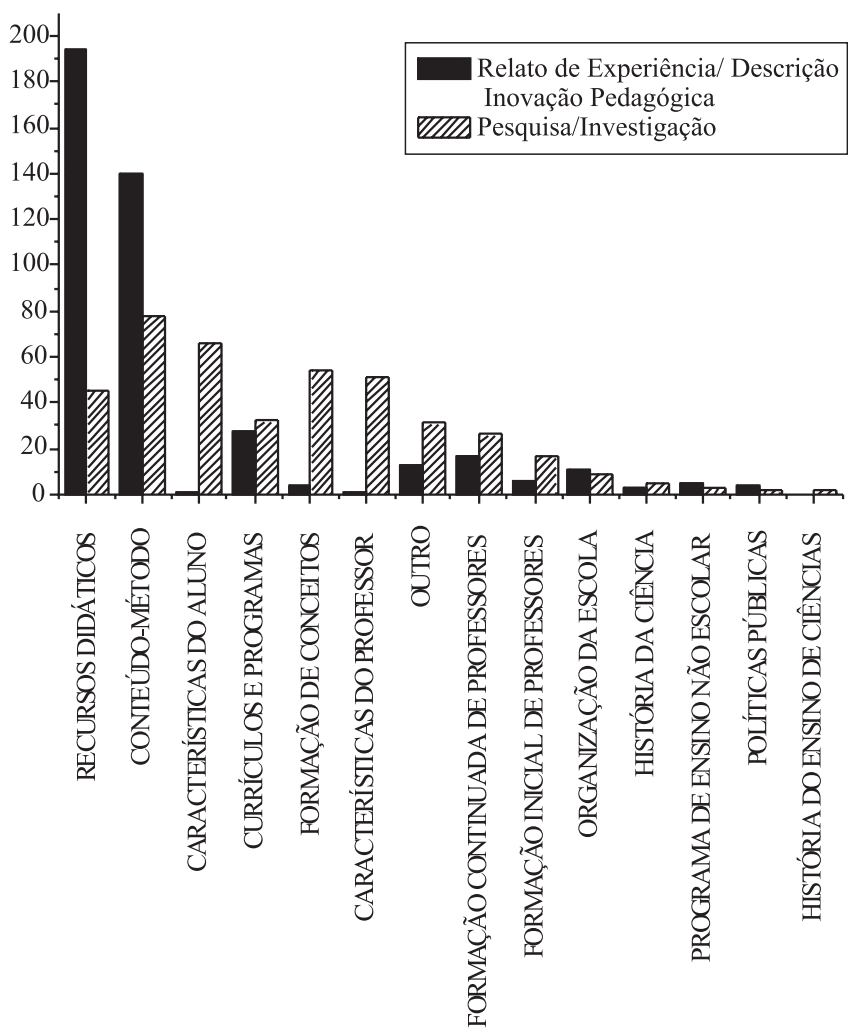

Figura 4. Número de trabalhos, nos diversos focos temáticos, classificados como trabalhos de pesquisa/investigação e como descrições de inovações pedagógicas e relatos de experiência

Segundo Schnetzler, ${ }^{4}$ considerando apenas os trabalhos de pesquisa/investigação, as temáticas mais freqüentemente exploradas nos trabalhos das RASBQs no intervalo de 1977-2001 são relativas à aprendizagem, dificuldades e concepções dos alunos e a concepções e dificuldades dos professores. Tendo em vista que os focos temáticos Características do Aluno, Formação de Conceitos e Características do Professor, definidos no nosso trabalho como os sendo mais amplamente explorados, abarcam as referidas temáticas, podemos concluir que a preocupação na investigação das mesmas persiste nos grupos de pesquisa em Educação em Química no recorte histórico por nós analisado. A investigação sobre a Formação de Professores, em contrapartida, ganhou relevância nos últimos anos, dentro do contexto das RASBQs.

Cabe ainda destacar que os trabalhos que tratam de abordagens interdisciplinares, que no intervalo investigado por Schnetzler ${ }^{4}$ tinham uma baixa representatividade (aproximadamente 38 trabalhos) ganharam força. De fato, observamos no período por nós investigado (que é menor do que o investigado pela referida autora) um total de 39 trabalhos que tratam da temática, considerando apenas aqueles classificados exclusivamente no foco Conteúdo-Método, sendo que, conforme mencionamos anteriormente, em 15 deles, a palavra interdisciplinaridade (e/ou palavra correlata) já se encontra presente nos títulos dos trabalhos.

\section{CONSIDERAÇÕES FINAIS}

Este trabalho teve como objetivo oferecer ao leitor uma visão panorâmica de uma parte importante da produção acadêmica brasileira sobre o Ensino de Química nos últimos 8 anos: os trabalhos apresentados nas RASBQs, na seção de ED. A narrativa cronológica dos resumos investigados revela que este número tem aumentado consideravelmente com o passar dos anos, sugerindo o amadurecimento da área em estudo e o fortalecimento de uma comunidade preocupada com a melhoria do Ensino de Química no Brasil.

Na narrativa que aponta para as regiões geográficas de produção dos trabalhos, evidenciamos uma maior participação de membros da comunidade acadêmica da região Sudeste em relação às outras regiões, principalmente em relação à região Norte. Podemos especular a respeito de alguns fatores que conspiram para a concretização de tal situação, entre os quais estão as diferenças encontradas nas condições de produção das pesquisas no Brasil, assim como no número e nas características de IES instaladas nas diferentes regiões, e ainda o local onde foram sediadas as RASBQs, geralmente na região Sudeste. O estabelecimento de parcerias sólidas entre pesquisadores das várias regiões brasileiras poderia contribuir para minimizar, em parte, a concentração da produção no Sudeste. No entanto, a análise dos dados obtidos sugere que esta prática não vem sendo adotada com freqüência pelos participantes das RASBQs.

$\mathrm{Na}$ organização da produção quanto ao nível escolar abrangido nos estudos, o Ensino Médio foi privilegiado, seguido pelo Ensino Superior, por trabalhos que se encaixam no descritor Geral e pelo Ensino Fundamental. Nesta perspectiva, também para o período investigado por Schnetzler, ${ }^{4}$ foi verificada uma pequena quantidade de trabalhos relacionados ao Ensino Fundamental. Ainda menos privilegiado que o Ensino Fundamental é o Ensino Infantil, sobre o qual nenhum trabalho foi produzido no período por nós investigado. Consideramos a existência de tal lacuna preocupante, uma vez que concordamos com Megid Neto ${ }^{5}$ sobre a importância do período no qual a criança se encontra na Educação Infantil para a sua formação intelectual e moral, bem como para a apropriação dos primeiros conhecimentos mais sistematizados no campo das Ciências.

No que diz respeito aos focos temáticos investigados nos trabalhos, destacam-se fortemente os focos Recursos Didáticos e Conteúdo-Método. Uma quantidade considerável de trabalhos foi também classificada nos focos Características do Aluno, Características do Professor, Currículos e Programas, Formação de Conceitos e Formação de Professores. Em contrapartida, os focos temáticos Organização da Escola, História da Ciência, Programa de Ensino Não-Escolar, Políticas Públicas, História do Ensino de Ciências e Filosofia da Ciência foram pouco privilegiados, sugerindo a existência de assuntos e questionamentos que precisam ser mais amplamente investigados no contexto da pesquisa em Educação em Química. Dentre os trabalhos classificados no foco temático Outro, destacam-se aqueles que tratam de exames vestibulares e os relacionados à linguagem e cognição, que aparecem com uma frequiência que chega a se igualar ou a ultrapassar a quantidade de trabalhos presentes em focos como História da Ciência e História do Ensino de Ciências. Assim, acreditamos que tais assuntos são merecedores de um foco temático específico quando tratamos de analisar produções acadêmicas da área de Educação em Química.

A análise dos trabalhos quanto ao gênero acadêmico indicou que a representatividade do número de trabalhos de pesquisa/investigação e de descrições de inovações pedagógicas e relatos de experiência é quase idêntica no período por nós investigado: 49,70\% dos trabalhos representam pesquisas/investigações e 50,30\% representam inovações pedagógicas e relatos de experiência. Constatação semelhante havia sido anteriormente alcançada por Schnetzler. ${ }^{4}$ Acreditamos que este resultado deixa transparecer, pelo menos em parte, o perfil dos participantes das RASBQs.

\section{REFERENCIAS}

1. Ferreira, N. S. A.; Educ. Soc. 2002, 79, 257.

2. Ferreira, N. S. A.; Tese de Doutorado, Universidade Estadual de Campinas, Brasil, 1999. 
3. Bejarano, N. R. R.; Carvalho, A. M. P.; Educación Química 2000, 11, 160 .

4. Schnetzler, R. P.; Quim. Nova 2002, 25, 14.

5. Megid Neto, J.; Tese de Doutorado, Universidade Estadual de Campinas, Brasil, 1999.

6. Soares, M. B.; Alfabetização no Brasil: o estado do conhecimento, INEP/REDUC: Brasília, 1989.

7. Resumos do XIII Encontro Nacional de Ensino de Química, Campinas, Brasil, 2006.
8. Resumos da 30a Reunião Anual da Sociedade Brasileira de Química, Águas de Lindóia, Brasil, 2007.

9. http://llates.cnpq.br, acessada em Novembro 2007.

10. Santos, W. L. P.; Mól, G. S.; Química e Sociedade, Nova Geração: São Paulo, 2003.

11. http://www.projetos.unijui.edu.br/gipec, acessada em Novembro 2007.

12. http://www.capes.gov.br, acessada em Novembro 2007.

13. http://cenp.edunet.sp.gov.br, acessada em Novembro 2007. 